\title{
Chapter 2 \\ Regenerative Design Tools for the Existing City: HBIM Potentials
}

\author{
Carlo Bianchini, Martina Attenni, and Giorgia Potestà
}

\begin{abstract}
The first 25 years of the so-called 'digital revolution' have deeply changed the methods and tools of our interaction with the 'architectural domain'. Traditional lines sketched on traditional paper have been soon replaced by digital mathematical entities created by Computer Aided Design (CAD) systems. Nowadays, we are witnessing a similar shift this time from CAD to the Building Information Modelling (BIM), a system that shows the ability to manage the fragmented but interconnected information needed in building workflow in an 'all-inone' environment. However, while BIM is already a powerful option for new structures, for existing ones (especially when historical) it still reveals inadequate. This issue, seriously affecting the future of the built environment, cannot be ignored in order to control the 'shaping' of buildings and cities and especially when their design aims at becoming 'regenerative'. In this framework, this chapter will try to outline the many difficulties connected with the application of BIM to the existing building stock: a problem that is generally regarded as 'sectorial' but that on the contrary will be crucial in view of a probable generalized adoption, considering that existing constructions represent about $70 \%$ of the whole European stock.
\end{abstract}

Keywords BIM $\cdot$ HBIM $\cdot$ Level of development $\cdot$ Level of detail $\cdot$ Level of reliability $\cdot$ Semantic structuring

\subsection{Introduction}

Existing buildings always represent for designers a prickly subject to handle. The core of the problem is that they keep undisclosed the majority of information about their inner nature, structure and consistency. Designers and all other actors involved in their transformation (restoration, retrofitting, rehabilitation etc.) must address this

\footnotetext{
C. Bianchini $\cdot$ M. Attenni $(\bowtie) \cdot$ G. Potestà

Department of History, Representation and Restoration of Architecture,

Sapienza University of Rome, Rome, Italy

e-mail: carlo.bianchini@uniroma1.it; martina.attenni@uniroma1.it;

giorgia.potesta@uniroma1.it
} 
issue and continuously try to fill the gap between the desirable and available information (Bianchini, Inglese, Ippolito, Maiorino, \& Senatore, 2017).

This well-known condition has been always assumed as a constraint by designers, a sort of red line to coexist with during any project involving existing buildings (Brusaporci and Trizio, 2013).

The first 25 years of the so-called digital revolution have deeply changed this consolidated scenario. Digital technologies have in fact produced a wide bundle of hardware and software tools paving the way to a renovated interaction between our real world and its virtual version (Addison \& Gaiani, 2000; Carbonara, 2009). On one side, terrific advancement has been made in the field of capturing data from objects (Bianchini and Russo, 2018); on the other, the digital modelling software has disclosed the possibility of virtually reconstructing them, interacting with them and simulating their possible transformations (Bianchini, Viscogliosi, \& Aglietti, 2017).

Core of this interaction is the Model, namely the virtual simulacrum of a real element, which represents the goal and the medium of this interaction (Bianchini, Inglese, \& Ippolito, 2016b).

While for many years now the Model has been a major topic of research (and concern) for scholars and technicians, more recently the focus has been shifting towards the 'Modelling'. This last term does not refer in fact to the simple output, but better to the set of decisions and actions guiding the process of construction and information (in the sense of defining an informative content) of all digital elements composing, together, the final object (Bianchini \& Nicastro, 2018).

From this standpoint, Modelling certainly implies constructing in accordance with logical and practical rules not afar from those that typically govern a construction site. In fact, as in the building practice, we must disassemble the fabric into an analytic catalogue of elements and organize the site and the sequence of works, in the same way the construction of a 3D Model must approximately respect the same workflow and constraints. In a BIM process, the identification and generation of BIM digital objects is generally called Semantic Segmentation (Grussenmeyer et al., 2008).

In this framework, the construction of 3D Models is a real heuristic activity: differently from graphic 2D models (drawings), in a 3D Model one cannot afford to leave any portion of the object undefined, as anything can become visible and anything is visible during its exploration.

Moreover, buildings are a coordinated set of basic elements (Bianchini, Inglese, \& Ippolito, 2016a) following design patterns and construction workflows to a certain extent predictable and governable. Besides, any element must be augmented with additional content in order to show not only its quantitative properties (i.e. geometry) but also its qualitative ones (material, physical parameters, performance etc.).

BIM systems actually provide a digital environment capable to host, organize and interact with all this information by means of the 3D Model that, at a certain extent, could become an access door to the building's informative database. 
This well-known feature of BIM systems and models corresponds to their utmost benefit during the decision-making and construction workflow as it corresponds to an overall optimization of processes in terms of cost reduction and efficiency.

However, the potential impact of BIM complex informative models exceeds the mere technological sphere representing instead an actual cultural progress, thanks to their ability to foster the readings of architecture through its constitutive elements (Brusaporci, Maiezza, \& Tata, 2018).

However, BIM works quite well when addressing new buildings essentially because being ourselves the decision-makers, at least in principle, we can know in advance all information about both the elements and their assembling.

This mechanism fails if analysed in the context of existing buildings. Although they can be disassembled into recurring elements, yet their modelling (parametric and informative) is far more difficult. It must in fact deal with both the geometric conversion of the real-world continuity and the definition of its qualities and semantics. These problems must be regarded also in connection with the essential inelasticity of parametric modelling, subjected to digital 'libraries' of objects that predictably would clash against the holistic character of the built environment, especially when it is layered or deteriorated.

This evidence has led scholars and professionals to introduce a specific name for the BIM systems applied to existing buildings adding the prefix ' $\mathrm{H}$ ' that stands for Historic or Heritage.

Apart from this linguistic definition, the more the HBIM approach is studied and analysed, the more it appears separate from 'classic' BIM (López et al., 2018). Although sharing the same digital infrastructure, in fact, HBIM shows very specific problems, limits and workflows that in some occasions seem not to have much relationships with the ones typical of BIM (Baik, 2017).

\subsection{Knowledge Versus Modelling}

The study of any built artefact implies to the setup of a Knowledge System appropriate for collecting, storing and querying the information retrieved (Apollonio, Gaiani, \& Sun, 2013; Bianchini, 2014).

As mentioned in the previous paragraph, several are the components of this system: 'quantitative', (generally coming from surveying/diagnostic activities) and 'qualitative'.

While the former can be labelled as 'scientific', the latter draw instead on the scholar's sensitivity and skill, often the most relevant ingredient for understanding the essence of buildings.

This process is paramount when dealing with existing buildings when the construction of a consistent and rigorous multidisciplinary database represents a key task as well as the cooperation of different skills in suggesting interpretations that transcend the single expertise. 
Moreover, while Popper's irrefutability concept (Popper, 1963) still marks the qualitative component, the quantitative one depends on the contrary on Survey, one of the most acknowledged tool set up overtime by scholars in order to enlighten the metric and geometric consistency of artefacts (Docci, Ippolito, \& Bianchini, 2011).

Survey actually encompasses the notion of 'measurement', that is, the possibility of turning into quantity some qualities of a phenomenon by using the ratio between the measured quality and a suitable unit of measure.

However, measurement itself cannot give access to the qualitative level of information that instead can be collected and interpreted by mining data from very different (in many cases scattered) 1D (texts) and 2D (images, drawings, instrumental readings etc.) sources. In this phase, we cannot even neglect less structured information coming from intuitions or suggestions.

The 3D Model represents the synthesis of the process, more intellectual than operational, the Modeller (i.e. the maker of the Model) has used to show his/her reconstructive hypothesis. HBIM systems actually implement tools both to build the geometry of the model and to attach the related information to its single digital components. As for the first aspect, the leading BIM authoring software currently allows for an overall smooth editing and management of massive 3D data (point cloud) (Logothetis, Karachaliou, \& Stylianidis, 2017).

While the passing from a numeric to a geometric model implies the transition from isolated points (in billions by now) to a continuous surface (Mesh or NURBS Non-Uniform Rational B-Splines) or an aggregation of 3D solids, the construction of the BIM model encompasses an additional interpretative effort: the semantic structuring of its composing elements. This ontological and subjective step exceeds the simple geometric identification of elements. The Modeller, in fact, must shift from the real to the digital continuum (Inzerillo, Lo Turco, Parriniello, Santagati, \& Valenti, 2016) exploring a realm, hierarchical and additive, where all digital objects must find their own place within the BIM environment. Hence, the combination of these objects, subject to mutual relationships of nesting or belonging and to rules and constraints of interaction, controls the progressive construction of BIM and HBIM models.

Assuming the reading of an existing building not as a simply quantitative task, one must couple the mere metric investigation to the study of the cultural, technological and historical features making that particular object 'one of a kind'. Currently, automatic systems are not a viable option in order to reach this level of understanding and this is why the semantic structuring of the HBIM model is crucial to transcend the mere taxonomic description of buildings (Acierno, Cursi, Simeone, \& Fiorani, 2017; (; Fallavolita, Ballabeni, Foschi, \& Perugini, 2015; Quattrini, Pierdicca, \& Morbidoni, 2017).

Although concerning Cultural Heritage computer-based visualizations, still the London Charter (Denard, 2016) provides many hints about the role of new digital tools in connecting different pieces of information. In particular, the Charter defines as Dependency Relationships the implications (that) each piece of knowledge might be for each other piece of knowledge by means of the iterative, systematic comparison between hypotheses and data. These remarks can be usefully adopted to describe 
also the relationship between quantitative and qualitative information stored in a HBIM model.

\subsection{Geometry and Semantics in HBIM Models}

In the last years, the problems described in the previous paragraphs have been tackled in some research projects with the objective of outlining a common scientific framework.

As a collateral product, these projects have led to the setup of a workflow for the decomposition/recomposition of existing buildings in a HBIM environment based on geometry and semantics.

The main issues tackled are listed below:

- Semantic modelling versus continuity of surfaces

- Standardization of HBIM components versus geometric and material heterogeneity

- Reliability of models as ratio between a subjective version of the object and the almost objective captured data

The research presented in this chapter describes three different case studies: in Rome, the Faculty of Botany by the architect Giuseppe Capponi in Sapienza University Main Campus and the Temple of Claudius, and in Florence, the Baptistery of Saint John (see Fig. 2.1).

The Faculty of Botany is a rationalist building, easier (ostensibly) to model in a HBIM environment due to its typological, geometric-morphological and compositional clarity. The Temple of Claudius is instead a much-layered building, dating back to the first century $\mathrm{AD}$, with a strong archaeological character. The Baptistery of Saint John is a worldwide-celebrated monument that reached its current form mainly in the XIV/XV centuries.

The theoretical implications of the workflow described in this chapter are rather complicated because in many occasions the modelling must go beyond the measurable features of the artefact. As we have already mentioned in the previous paragraphs, this refers to the subjective skills and approach used by the Modeller during his/her interpretative work.

However, the collection and analysis of survey, semantic and typological data have proved to be necessary steps for the discretization of visible parts, the definition of materials, the conjecturing of construction rules and the identification of the transformations the building has undergone (see Fig. 2.2).

This cognitive aspect is also fundamental for the setup of consistent HBIM libraries. These repositories of digital objects provide in fact information (like materials and building components/nodes, their historical and cultural relevance and state of conservation) that go beyond the skin of the building. 

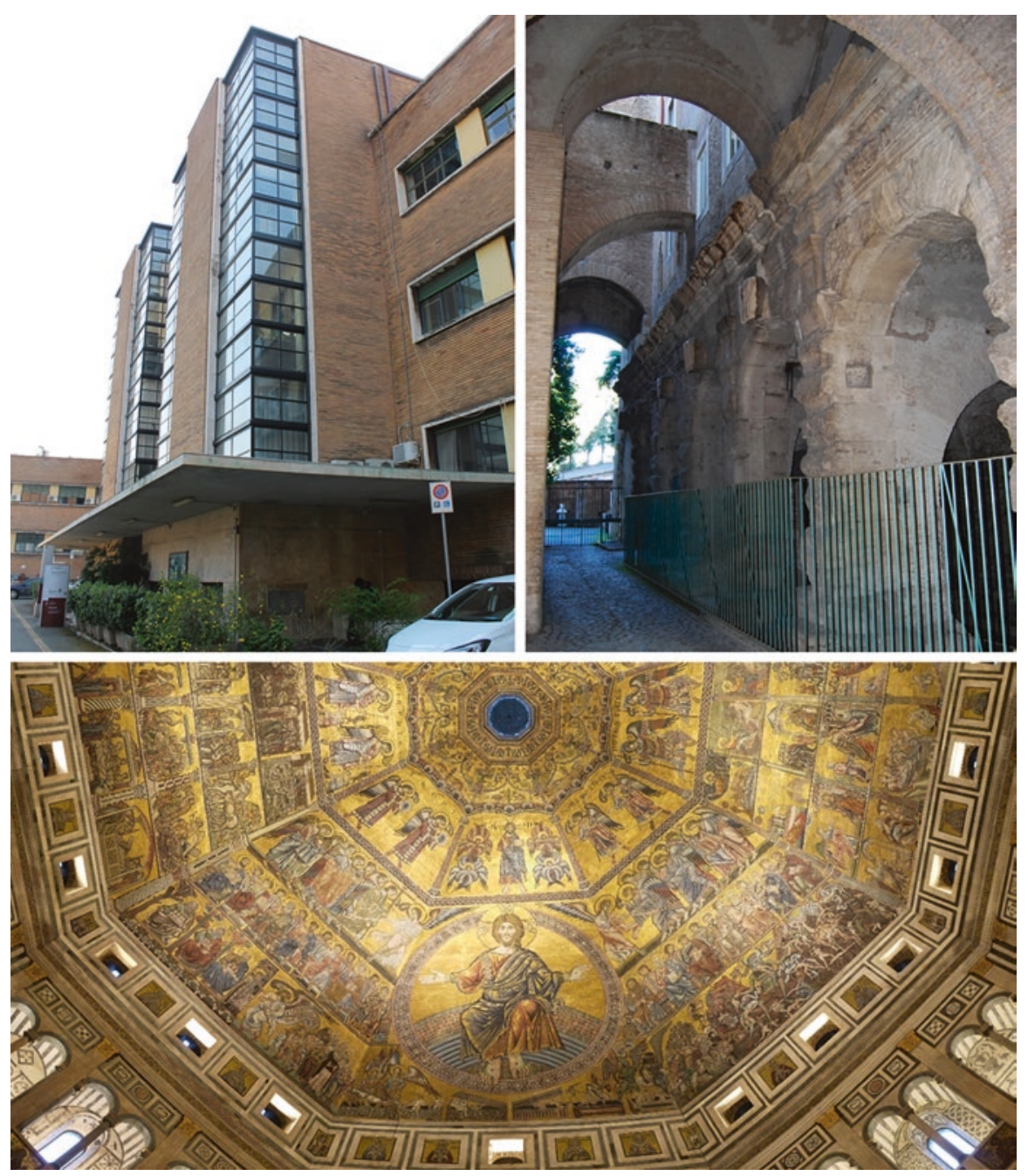

Fig. 2.1 The analysed case studies. Top left: the Faculty of Botany at Sapienza University (Rome); right: the Temple of Claudius (Rome); bottom: the Baptistery of Saint John (Florence)

However, parametric and informative modelling clash against the difficult geometrical shaping of the real-world continuity both in terms of poor libraries/reality correspondence and simple lack of information.

Referring to the Faculty of Botany, the coding and modelling of objects have mirrored the original design logic (see Fig. 2.3) trying to respect their serialization that has been managed in the HBIM process by acting on the dimensional parameters of structural elements and windows (see Fig. 2.4). 

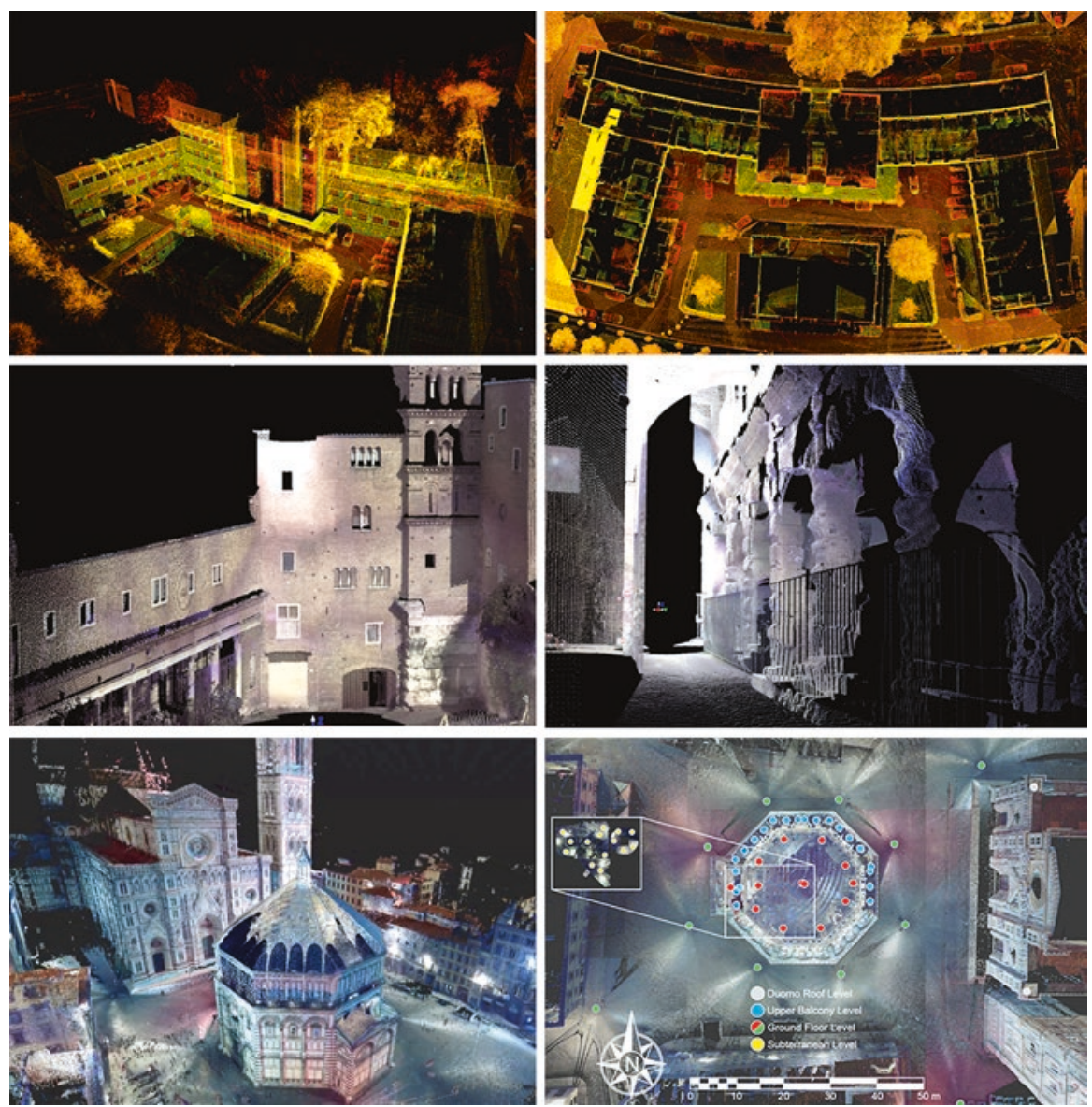

Fig. 2.2 Surveying of analysed case studies, views of the numerical model, RGB reflectance and RGB colour. Top: the Faculty of Botany at Sapienza campus, middle the Temple of Claudius; bottom: the Baptistery of Saint John

The 3D capturing campaign provided information about dimensions, geometry, materials and state of conservation of surfaces becoming, eventually, the actual backbone of the entire informative database.

For the Temple of Claudius, instead, it was impossible to refer to the original design and thus the surveyed data were taken as fundamentals for interpreting the irregularities of that layered complex while the proportional and metrological analysis guided the modelling phase (see Figs. 2.5 and 2.6).

For the Baptistery of Saint John, the approach was somewhat halfway between the previous two.

The original design was not available also in this case, but many documents were providing valuable information about its evolution starting soon after its completion. The comparison between this wide documentation and the detailed 3D data 

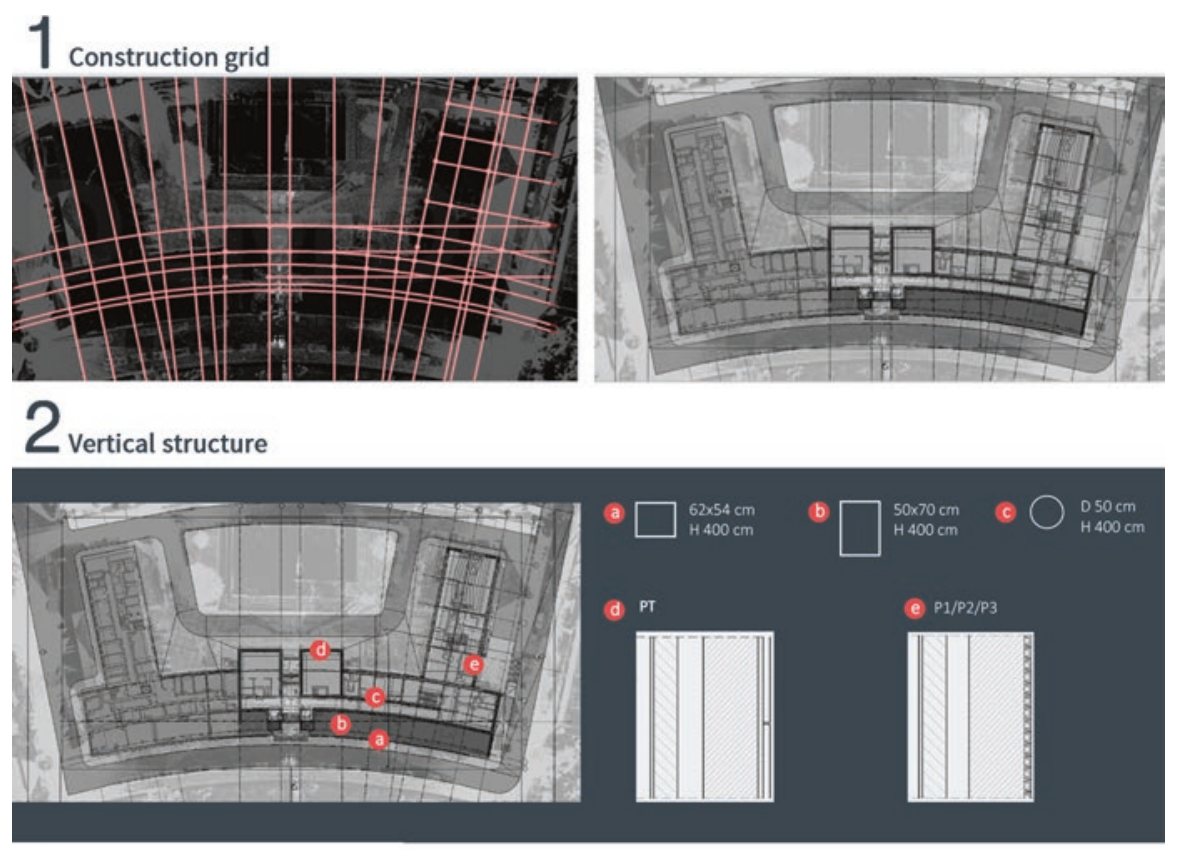

\section{Curtain wall/windows}
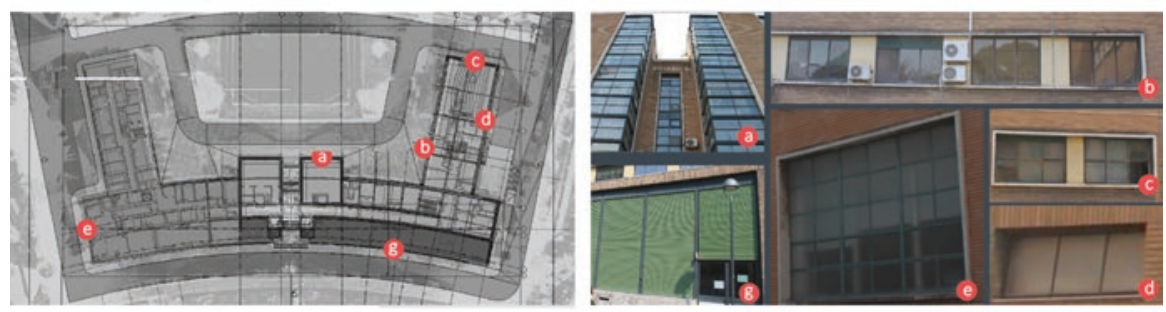

\section{Horizontal structure}
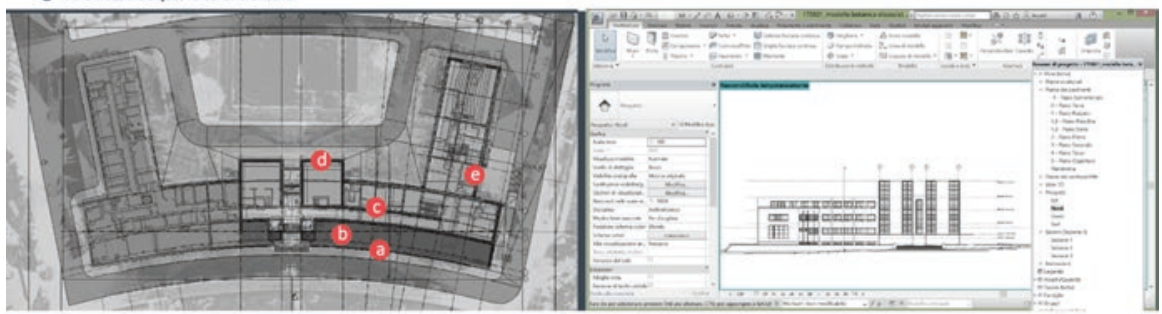

Fig. 2.3 The Botany Institute. Breakdown of architecture 

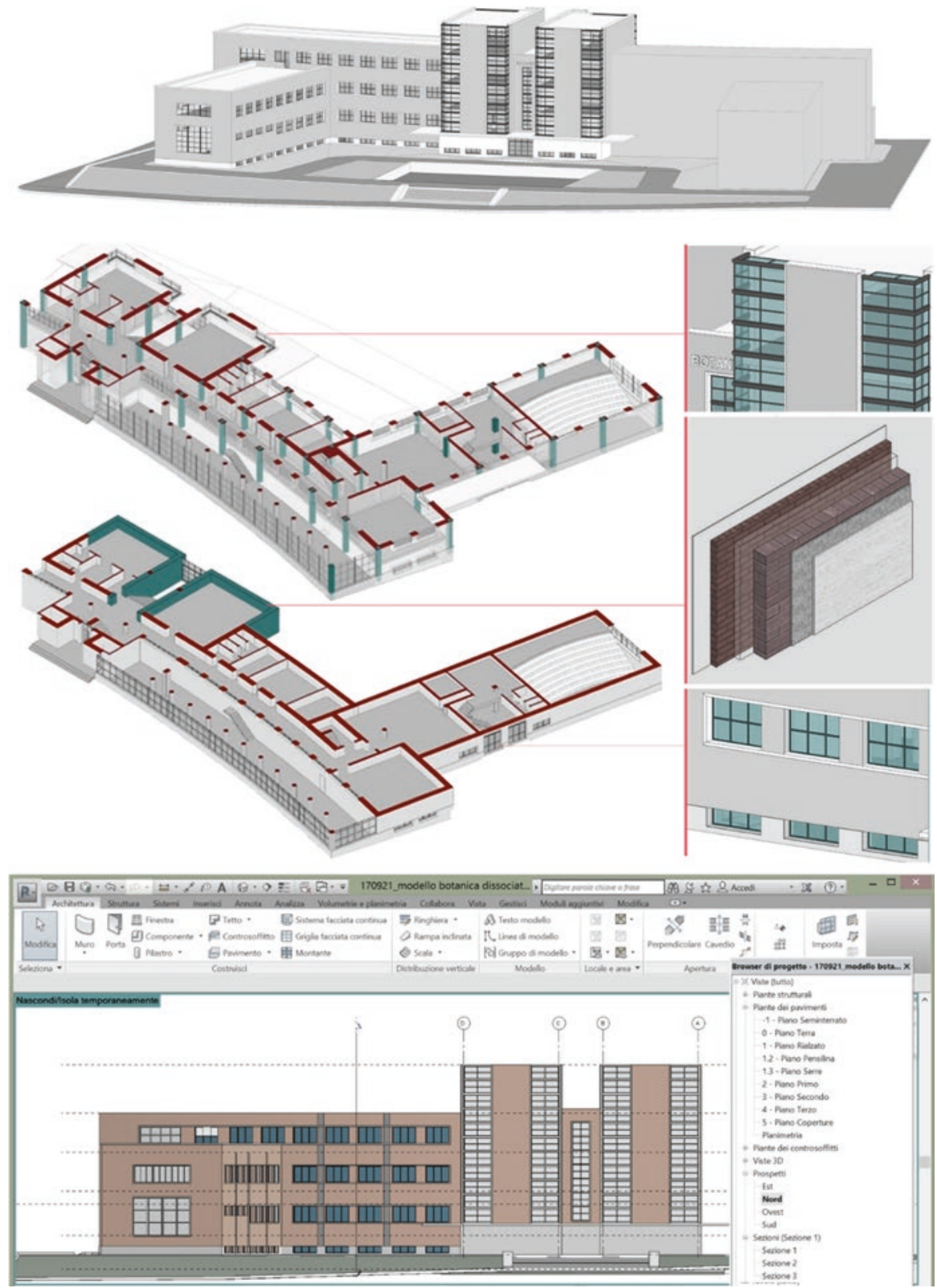

Fig. 2.4 The Botany Institute. Architecture reconstruction through BIM processes. Details of ground floor, windows and walls 


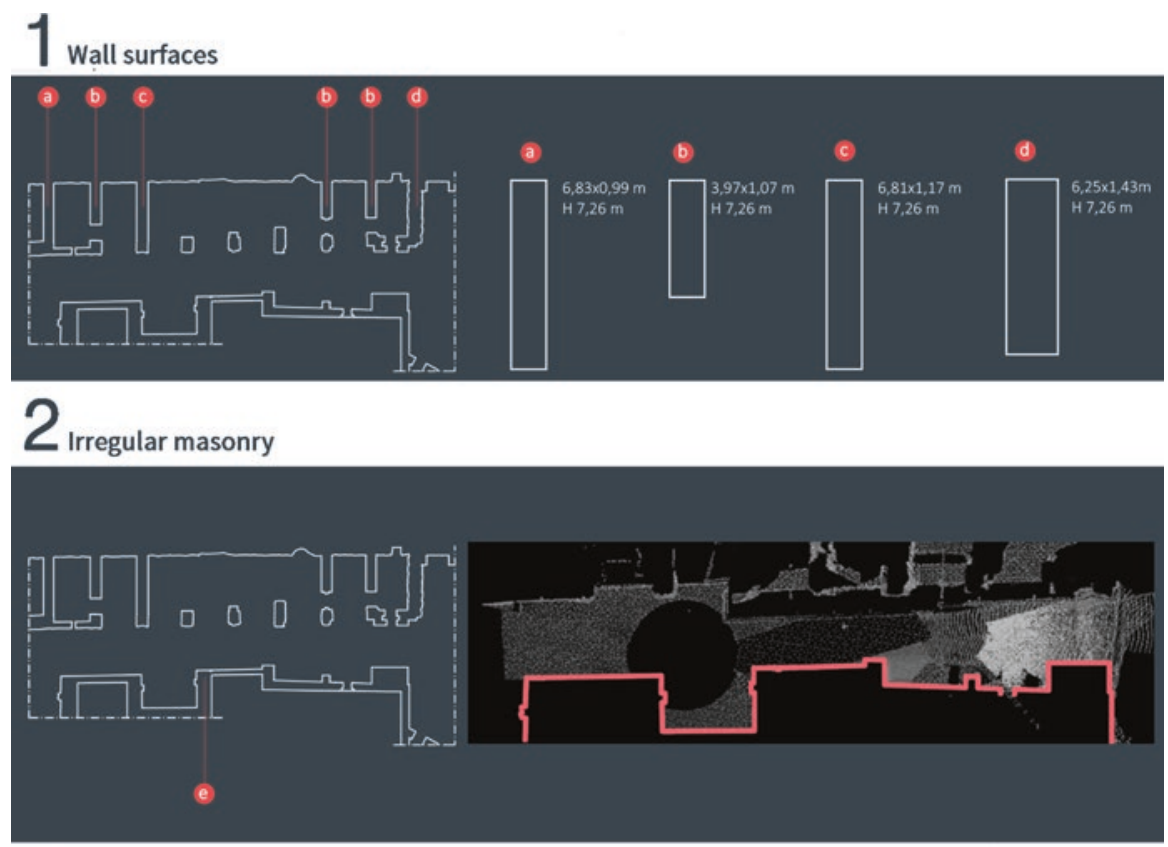

\section{3 vauts}

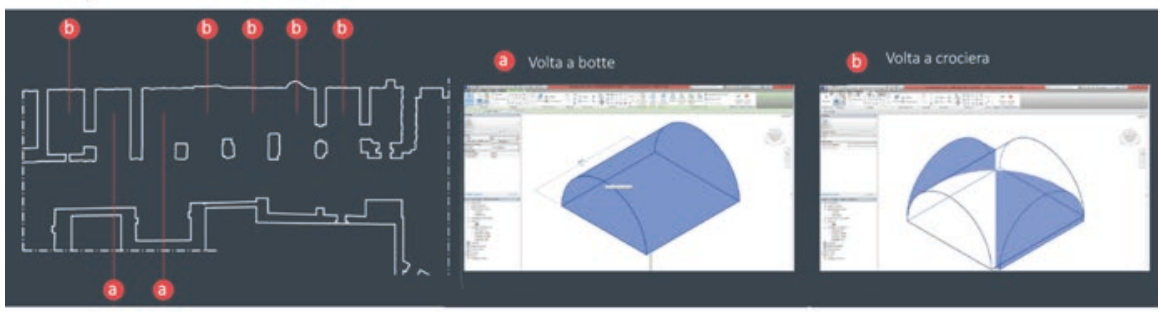

\section{Architectural elements}

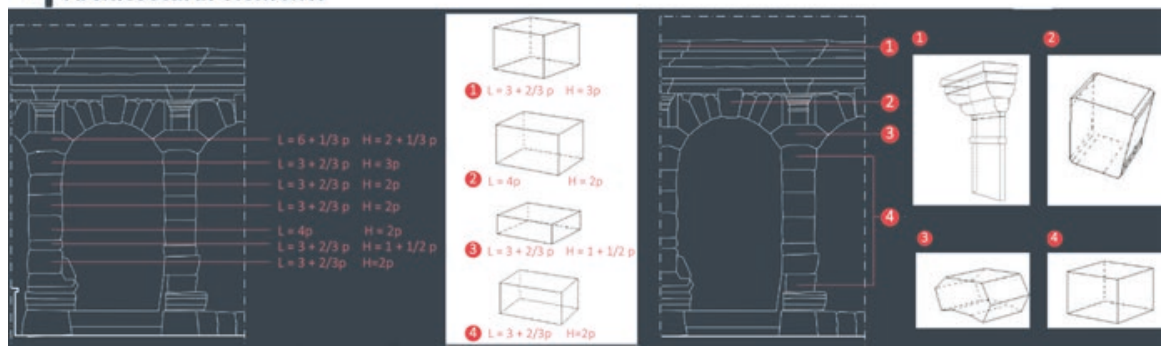

Fig. 2.5 Temple of Claudius. Breakdown of architecture 


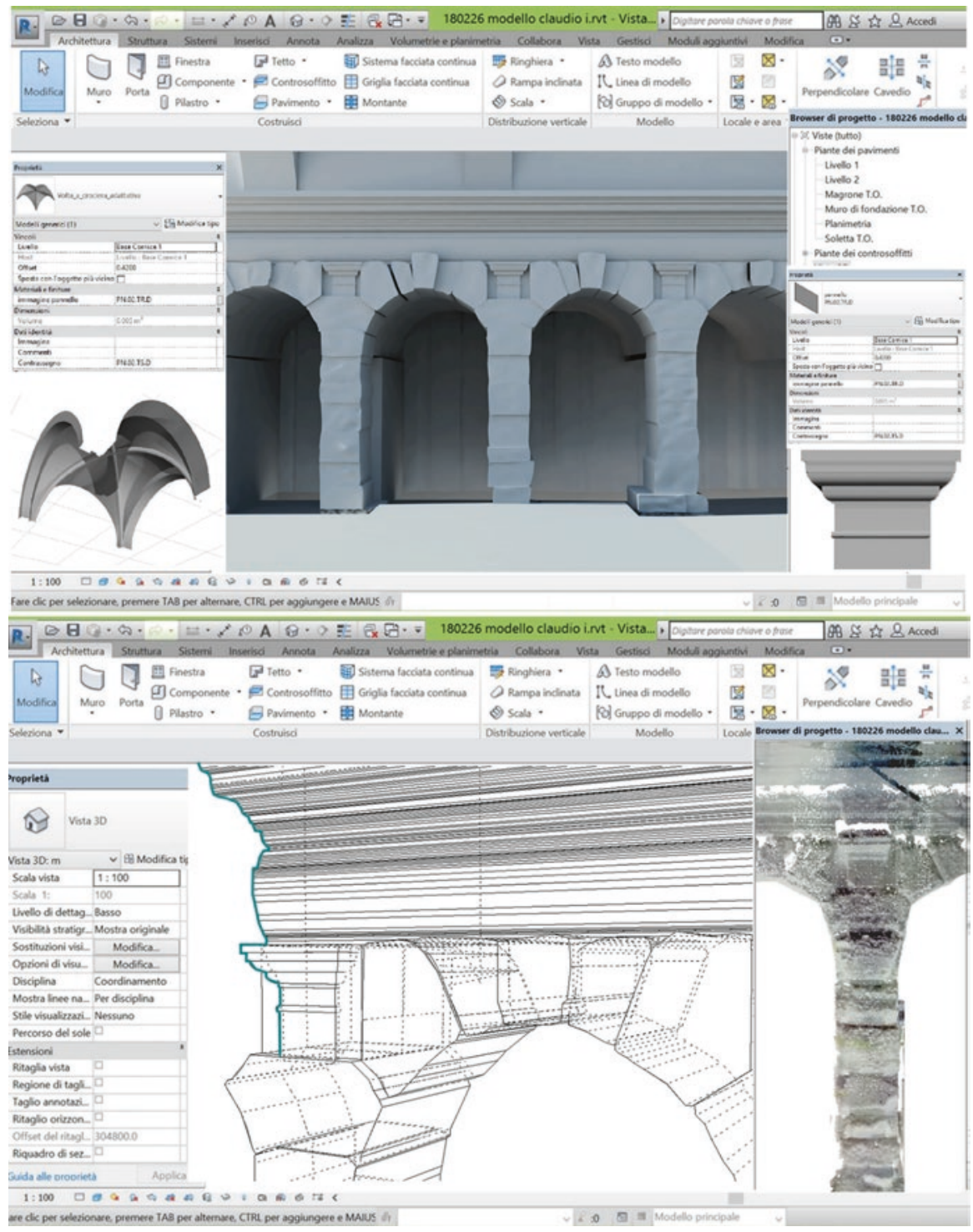

Fig. 2.6 Temple of Claudius. Architecture reconstruction through BIM processes: structural and architectural elements

coming from a survey campaign carried out in 2013 by the Center of Interdisciplinary Science for Art, Architecture and Archaeology (CISA3) from University of California San Diego led to the HBIM modelling of the monument (see Fig. 2.7).

After these preliminary analyses, we began to work at the HBIM model of our three case studies. 


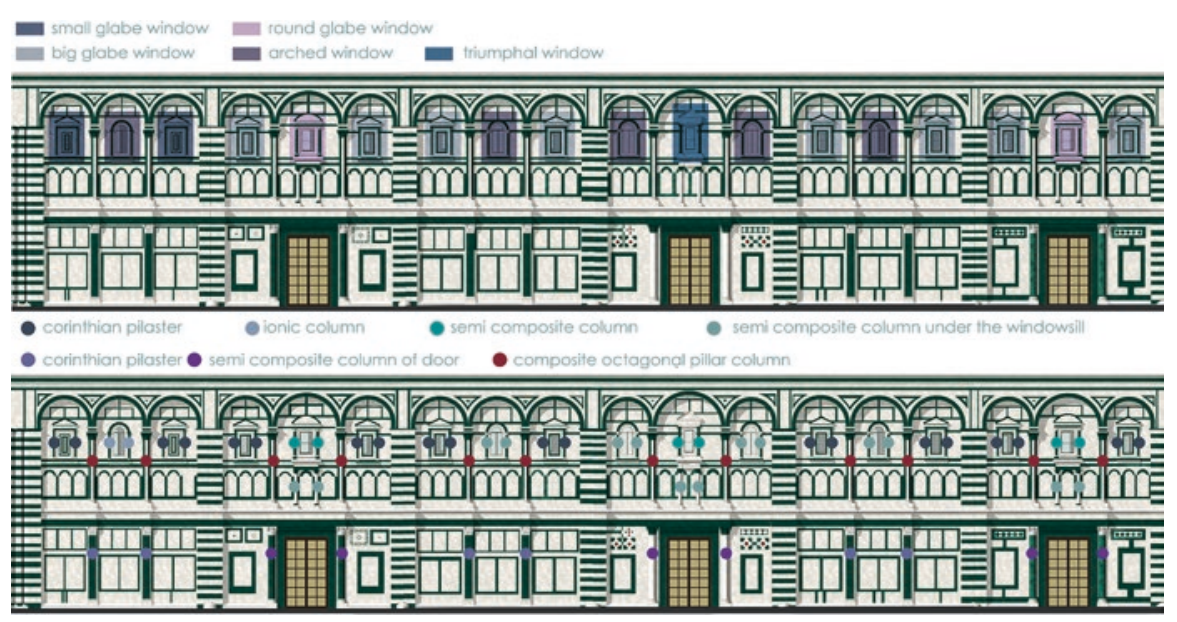

Fig. 2.7 Baptistery of Saint John. Breakdown of architecture

For the Faculty of Botany, we started from the analysis of 1D and 2D data coming from archival and bibliographic research, and from an in-depth analysis of the 3D data collected during a survey campaign. The data processing has been followed by a general setup of the HBIM model with the main objective of creating a database that could be enriched over time.

Given these theoretical and methodological remarks, the preliminary study on the most effective layout of virtual informative models has proved crucial and actually propaedeutic to the actual modelling phase.

In this gradual process of acquaintance and information structuring, we constantly tried to depict a workflow valid and coherent in terms of scientific rigor and of expected results. Thanks to the application to this first case study, we soon realized how much the HBIM systems could affect the methodological and procedural choices since the very early stages (i.e. since the survey project). While designing a HBIM-oriented survey, in fact, we must already imagine the working methodologies to be adopted in the modelling environment.

Therefore, we cannot establish a standard workflow valid regardless of the peculiarities of the object. On the contrary, we must provide tailor-made indications based on the preliminary study about the most appropriate approach vis-à-vis the decomposition and parameterization of the specific studied building. In brief, we should mistrust simplistic theorizations in favour of some-what holistic methods and strategies.

In our case, the different sub-models (for type and source) composing the general database coexist in the unique workspace created by the HBIM system. This is in fact the environment where the interactions among the 1D information, the 2D support drawings (including the project documentation) and the numeric model made by the captured point clouds (topographic, 3D scanning and Structure from Motion) have taken place. 
The goal of HBIM processes is to transform the material elements into digital correspondents: in our case the level of this relationship has been quite satisfactory as the model of the Institute of Botany corresponds quite closely to its present state. In other words, the differences between the original and current layout introduced by the construction itself still allow for a full exploitation of the parametric modelling approach typical of BIM systems.

This method had to undergo some modification for the Temple and the Baptistery.

As for the latter, although we have no trace of the original design, we could nonetheless guess much information from the documents and the many available drawings. Its original layout, even if with less reliability in comparison with Capponi's project blueprints, was still a sound option to start the modelling.

Yet in this specific case, we experimented an automatic approach to the semantic segmentation of part of the building applying a deep learning algorithm (Bengio, Courville, \& Vincent, 2013). In brief, this particular method uses artificial neural networks with the objective of performing complex recognition tasks. In our case, we adopted a supervised learning approach based on a set of already available training examples.

In our preliminary tests this method has shown an interesting impact due to its ability to segment and organize potentially any model in the form of a knowledge system. The algorithm, in fact, can help on one side in disassembling the building in a collection of hierarchically organized elements referred to a specific architectural vocabulary. On the other, the segmentation of the model into sub-elements can be based on the analysis and composition of the formal structure of objects, organized in hierarchical levels and aggregation's classifications.

Nonetheless, these systems are still quite rudimental even if promising. This is why we still had to analyse manually how all the identified objects were assembled (typologically and morphologically), to understand and establish how each element was made and how it referred to the others within the model.

The simplifications and approximations made for the Temple of Claudius aimed instead at finding a balance between a geometric and aggregative logic of elements and the holistic character of the artefact.

The breakdown of its components starting from its design layout would have made in fact no sense being what we see today only a small part of the huge ancient complex it used to be.

In this case, the modelling could refer to evidences coming almost completely from the $3 \mathrm{D}$ capturing of present remains, thus leaving to the subjective interpretation of the Modeller the construction of the HBIM model exploiting essentially proportional, stylistic and comparative analysis.

The first, in particular, enlightened a number of compositional rules and the basic module used both in the plan and in the elevation components suitable for guiding the parametric modelling phase.

The proportional rigor of the bays and of the blocks that make up the pillar's clashes, however, with the rear wall structures, characterized instead by sections and profiles in which it is not possible to trace a regular geometry. 
The modelling of travertine blocks has been subjected to the above-mentioned constraints. The analysis of the dimensional differences and proportional ratios led us to use as a parameter the generator module. In this framework, we treated individually the capitals of the pilasters, the hexagonal blocks and finally the key stones, avoiding considering the slightest local variations.

The capitals were modelled as nested families while the architrave was constructed identifying the mouldings directly in the point cloud. As for the wall surfaces, generally showing irregular sections, we generated profiles every $20 \mathrm{~cm}$ and, finally, for the barrel and rib vaults, we adopted this same approach varying though the dimensions of the profile.

\subsection{Level of Development, Level of Detail and Level of Reliability}

The activities performed on the previous case studies have pointed out some key general issues related to the international standard parameters used in the BIM and HBIM process, that is, the Level of Development (LOD) and the Level of Detail (LoD). Whereas the first intends to 'measure' the reliability of the information characterizing a BIM model, the second defines the graphic detail of digital objects in case of visualization or representation (Rossi \& Palmieri, 2019).

The increasing importance of BIM in the construction workflow justifies a deep discussion about the traditional concept of graphic detail in comparison with the LOD of BIM models (Rossi \& Palmieri, 2019). It has become evident, in fact, that there is a certain confusion about the real meaning of LoD and LOD among the various actors involved in the BIM process (see Fig. 2.8).

Assuming that it is somehow 'natural' for a BIM model to increase its informative content as the project proceeds, the first information associated with the model is usually referring to the starting situation, moving then to the concept, the executive layout up to the 'as-built' after the construction.

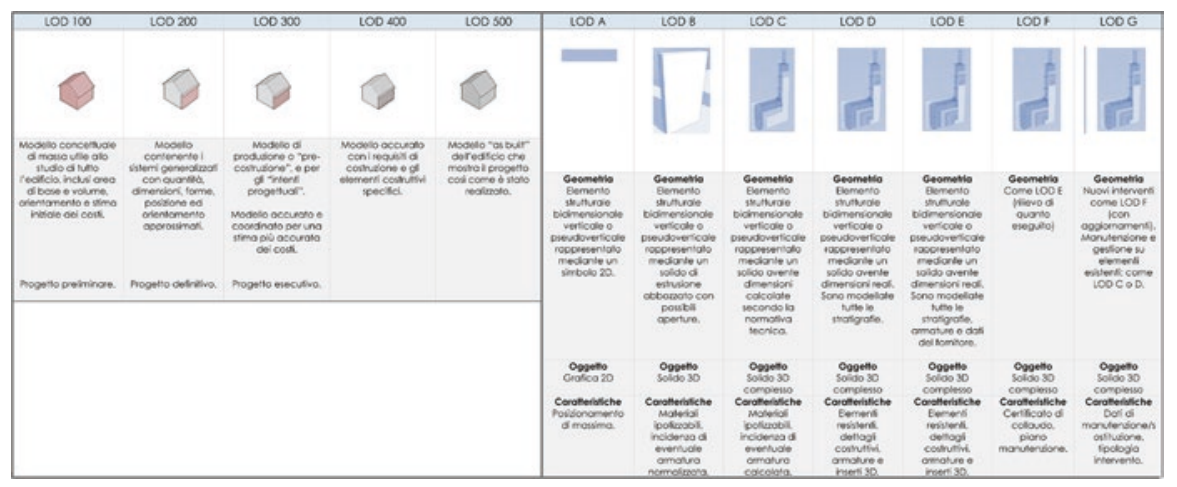

Fig. 2.8 Level of Development and the Level of Detail in BIM processes 
This workflow implies development in terms of both geometry and information that for many reasons tend to advance at different speeds.

When we consider an existing building, we face more or less the same problems, although with some substantial differences. First, the starting level is already an 'asbuilt' (or better an 'as-is') where the current situation is the building in front of us, characterized by a series of attributes not homogeneously known and knowable.

LoDs aim at precisely defining the level of detail of the various types of information associated with the model: in the initial phases of a BIM-oriented design, in fact, the commissioner would draw up a document named EIR (Employer's Information Requirements) containing the fundamental requirements to be included in the design.

The definition of these Levels is a topic addressed by two important regulatory references, one American and one Italian.

In the American context, the American Institute of Architects (AIA) has published a LOD framework for the AIA Protocol G202-2013 Building Information Modelling, where the term LOD refers to the Level of Development in terms of content associated with the modelled elements. 'Level of Development' is used instead of 'Level of Detail' because an element, apparently detailed on screen, could nonetheless show a rudimental geometry. According to this document, the development achievable through the drafting of a model within a BIM project is divided into five levels arranged by hundreds. From the LOD 100 in which the element is represented in a generic way, to the LOD 500 where the element strongly corresponds to the real one being an 'on site confirmed' representation.

The Italian legislation (STANDARD UNI 11337-4: 2017) provides an alternative articulation of LODs ordered in alphabetical sequence: levels from A to E correspond to 100/500. However, in this case, we find additional levels $F$ and $G$ in comparison with the American rule.

The F level refers to the state of the element detected on the site (as built) defining also its maintenance, management and/or repair works to be performed over a period. The LOD G, instead, deals with the updated digital version of an element during a certain period. In other words, it aims at providing information about the changes occurred during an interval of time due to its transformations.

Modern BIM authoring software provides tools to model digital objects with different graphic detail, from a schematic display up to a high detailed one. Therefore, there seems to be a close analogy between LOD and LoD so that we can easily conclude that simply increasing the detail of an object we can pass from one LOD to another assuming the Level of Development as equivalent to its graphic details.

Reality is quite different though. While modelling a 3D component, in fact, we can define progressively different LODs affecting its Level of Development and its features but not necessarily its actual geometric detail. In this framework, LODs can differ only for the attributes of the BIM object, that is, their Level of Information (LOI). On the other hand, however, any BIM object in its higher LODs must show correspondingly higher non-graphical information (the info attributes) and this evidence makes the sequence of LODs somehow independent from the Level of Detail that seems to describe only the geometric component of the modelled element. 


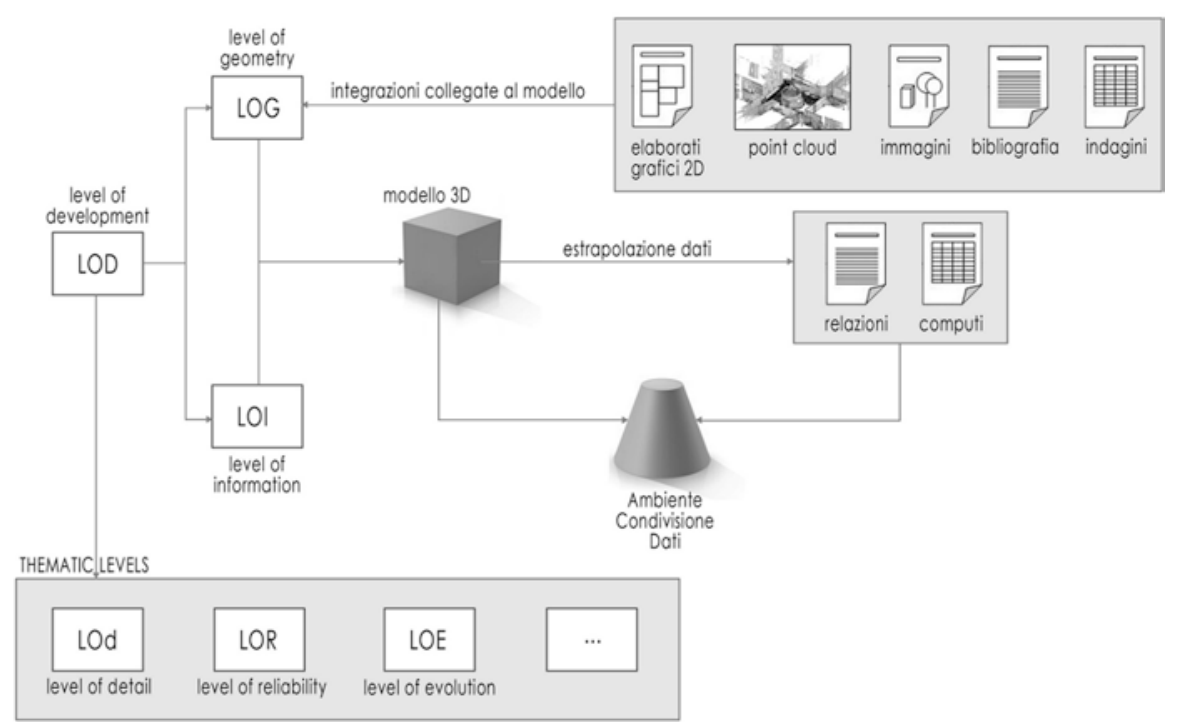

Fig. 2.9 Level of Details, Level of Reliability and the Level of Evolution in BIM processes

We can conclude that LODs are somehow independent from LoDs and actually intend to provide a standard for digital objects' consistency (see Fig. 2.9).

Still they do not take into account the quality of the information on which they are constructed. In any HBIM model, in fact, objects can vary a lot in term of reliability either because of the quantity of information available or of the quality of the Modeller's reading.

This is the reason why we concentrated on the coding of the Level of Reliability (LOR), an additional parameter aiming at assessing the coherence of the workflow guiding the generation of digital objects in a HBIM model. It is actually a numeric score resulting from the balancing of several factors considered as individual items and with respect to their general role within the model. Besides, we outlined some key aspects that could influence the LOR of one single object, of a collection of objects and eventually of an entire HBIM model.

The LOR coding considers the geometric reliability of digital objects together with their ontological correspondence to the real item they represent.

The following factors seem to have a strong influence on the geometric reliability of the model:

- Parameterization of the geometric shape

- Acknowledgement of compositional and geometric rules

- Availability of archival sources

- Comparison between the measured data and the model constructed

- Access to metadata associated with the capturing phase 
The ontological correspondence of digital objects is instead influenced by factors more difficult to analyse. They are in fact the product of more subjective tasks but also conditioned by the issue of 'going beyond' the skin of the building. At a certain extent, the Modeller is somehow 'obliged' to establish also the tectonic rules of digital objects populating the BIM environment.

In this framework we took into account:

- The evolutionary phases of the object

- The materials used and construction techniques

- Supplementary investigations (e.g. stratigraphy, layout of architectural or structural elements etc.)

- Assessment of construction technologies or materials by similarity

- Assessment of the state of conservation of materials

Given the previous general parameters, the LOR takes the form of a numeric scale spanning from 0 to 10 as you can see in the prototype diagram associated with a real architectural element and its digital doppelganger. Moreover, the diagram, helpful to evaluate the LOR key influencing factors, can be also beneficial while 'decomposing' the built artefact. Depending on the level of correspondence with the established key factors, for each item a score ranging from 0 to 2 has been proposed (see Fig. 2.10).

\subsection{Conclusions}

HBIM is a part of the wider processes related to the Heritage Building Information Modelling. Differently from conventional BIM, the HBIM, dealing with existing artefacts, must consider some additional issues connected with the knowledge of the building 'as-it-was' and 'as-is'.

If capturing technologies do play a very relevant role in freezing the geometric shape of objects, nevertheless much effort has to be put in retrieving additional information to increase the level of knowledge. This information can be 1D or 2D.

On that basis, the Modeller becomes the main character in the construction of the HBIM model, as it is his /her responsibility to choose how to disassemble and reassemble the existing object in the digital space.

Furthermore, the parameters that internationally describe the HBIM process make some confusion between the Level of Development and the Level of Detail of any element. While the former can describe quite well the position of a digital object in the BIM progression in terms of both development and information, the latter seems only to refer to its geometric features.

Finally, we dealt with the problem of assessing the informative content of objects according to its reliability. In this framework, we proposed the introduction of the Level of Reliability for BIM objects as the necessary methodological premise to make BIM systems an actual tool also for knowledge enhancement. 


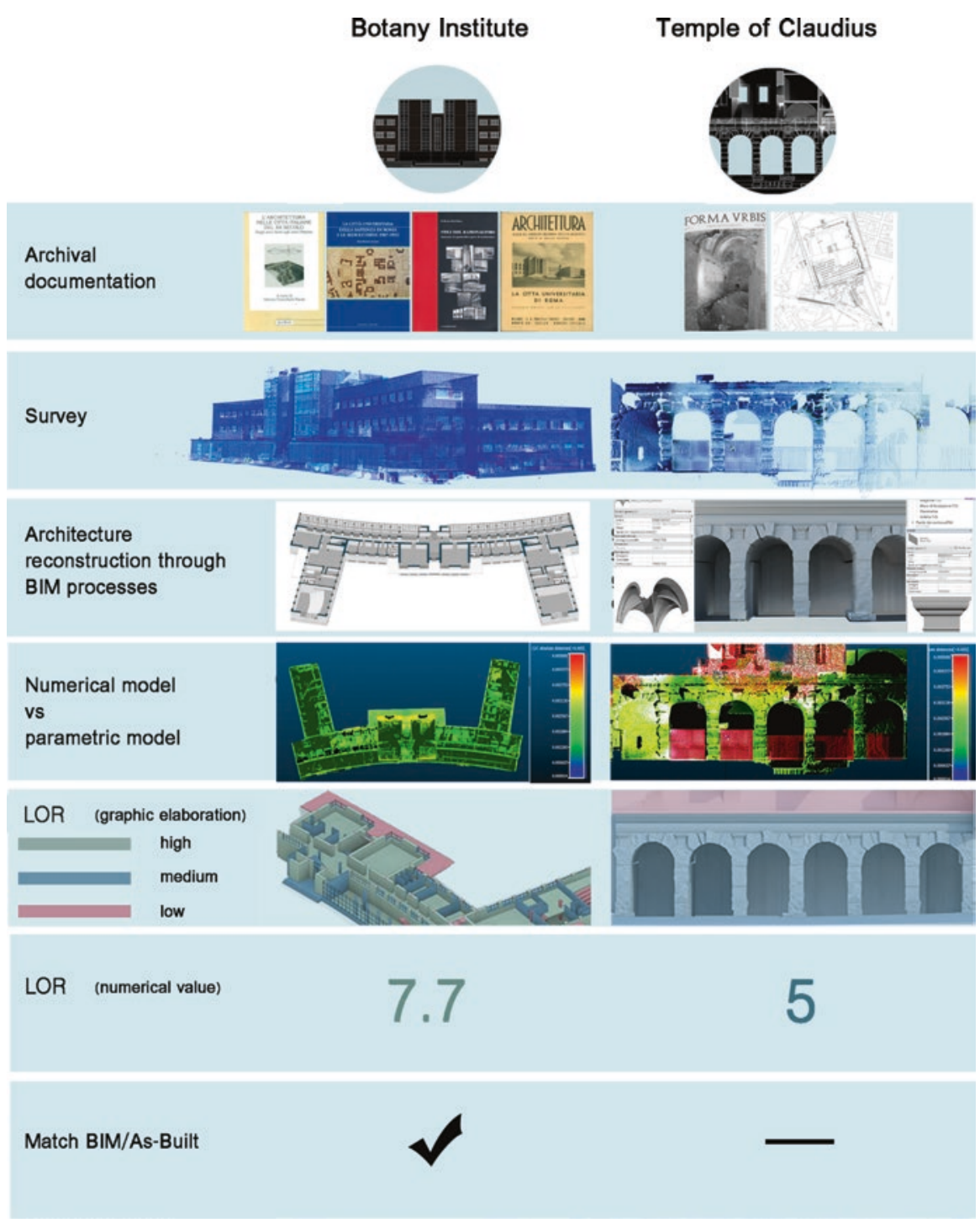

Fig. 2.10 The Botany Institute and the Temple of Claudius. Comparison of the processes and LoR

Knowledge is in fact a gradual process strongly related to the results of new investigations from which new information is generated and accumulated. This same rule seems to be applicable to the HBIM environment too, at least to its informative components. For this reason, specific protocols referring to investigation methods and objectives (as archival and bibliographic research, diagnostic and survey activities) could become themselves components of the HBIM workflow. Besides, thanks to the LOR diagrams, the information contained in the HBIM database will lead to more enhanced and reliable models (Table 2.1). 
Table 2.1 The Botany Institute and the Temple of Claudius, level of reliability in BIM processes

\begin{tabular}{|c|c|c|c|c|c|}
\hline \multicolumn{4}{|c|}{ Level of reliability LOR } & $\begin{array}{l}\text { Botany } \\
\text { Institute }\end{array}$ & $\begin{array}{l}\text { Temple of } \\
\text { Claudius }\end{array}$ \\
\hline \multirow[t]{3}{*}{$\begin{array}{l}\text { Geometrical } \\
\text { features }\end{array}$} & Free form & $\begin{array}{l}\text { Symbol/simplification } \\
\text { of geometry }\end{array}$ & 0 & \multirow[t]{3}{*}{2} & \multirow[t]{3}{*}{1} \\
\hline & \multirow[t]{2}{*}{ Geometric shape } & Parametric modelling & 1 & & \\
\hline & & Geometrical modelling & 2 & & \\
\hline \multirow[t]{3}{*}{ Surveying data } & No survey & $\begin{array}{l}\text { Simplification of } \\
\text { geometry }\end{array}$ & 0 & \multirow[t]{3}{*}{2} & \multirow[t]{3}{*}{2} \\
\hline & \multirow[t]{2}{*}{ Survey } & $\begin{array}{l}\text { Not integrated } \\
\text { surveying }\end{array}$ & 1 & & \\
\hline & & Integrated surveying & 2 & & \\
\hline \multirow[t]{3}{*}{$\begin{array}{l}\text { Specialist } \\
\text { investigations }\end{array}$} & $\begin{array}{l}\text { Not available or no } \\
\text { reliable data }\end{array}$ & $\begin{array}{l}\text { Hypothetical } \\
\text { information }\end{array}$ & 0 & \multirow[t]{3}{*}{$\mathbf{0}$} & \multirow[t]{3}{*}{$\mathbf{0}$} \\
\hline & \multirow[t]{2}{*}{ Available data } & Generic information & 1 & & \\
\hline & & Specific information & 2 & & \\
\hline \multirow[t]{3}{*}{$\begin{array}{l}\text { Archival } \\
\text { documents }\end{array}$} & $\begin{array}{l}\text { Not available or no } \\
\text { reliable data }\end{array}$ & $\begin{array}{l}\text { Hypothetical } \\
\text { information }\end{array}$ & 0 & \multirow[t]{3}{*}{2} & \multirow[t]{3}{*}{1} \\
\hline & \multirow[t]{2}{*}{ Available data } & Generic information & 1 & & \\
\hline & & Specific information & 2 & & \\
\hline \multirow[t]{3}{*}{ Physical features } & Free form & $\begin{array}{l}\text { Hypothetical } \\
\text { information }\end{array}$ & 0 & \multirow[t]{3}{*}{2} & \multirow[t]{3}{*}{1} \\
\hline & \multirow[t]{2}{*}{ Geometric shape } & Generic information & 1 & & \\
\hline & & Specific information & 2 & & \\
\hline \multirow[t]{3}{*}{$\begin{array}{l}\text { Technological } \\
\text { configuration }\end{array}$} & $\begin{array}{l}\text { Uncertain or not } \\
\text { definable }\end{array}$ & $\begin{array}{l}\text { Symbolic or absent } \\
\text { articulation }\end{array}$ & 0 & \multirow[t]{3}{*}{1} & \multirow[t]{3}{*}{1} \\
\hline & \multirow[t]{2}{*}{ Verified or definable } & Generic articulation & 1 & & \\
\hline & & Specific articulation & 2 & & \\
\hline \multirow{3}{*}{$\begin{array}{l}\text { Conservation } \\
\text { status }\end{array}$} & Not analysed & Not definable & 0 & \multirow[t]{3}{*}{1} & \multirow[t]{3}{*}{1} \\
\hline & \multirow[t]{2}{*}{ Analysed } & $\begin{array}{l}\text { Defined through } \\
\text { external links }\end{array}$ & 1 & & \\
\hline & & $\begin{array}{l}\text { Defined through digital } \\
\text { objects }\end{array}$ & 2 & & \\
\hline \multirow{3}{*}{$\begin{array}{l}\text { Compliance or } \\
\text { congruence checks }\end{array}$} & Not checked & Not verified & 0 & \multirow[t]{3}{*}{2} & \multirow[t]{3}{*}{1} \\
\hline & $\begin{array}{l}\text { Checked (comparison } \\
\text { between model, model }\end{array}$ & $\begin{array}{l}\text { Verified/not relevant } \\
\text { inconsistencies }\end{array}$ & 1 & & \\
\hline & checking) & $\begin{array}{l}\text { Verified/relevant } \\
\text { inconsistencies }\end{array}$ & 2 & & \\
\hline $\begin{array}{l}\text { Operational or } \\
\text { in-depth }\end{array}$ & $\begin{array}{l}\text { Not provided } \\
\text { Directions }\end{array}$ & $\begin{array}{l}\text { Absent indication/low } \\
\text { probability of profiting }\end{array}$ & 0 & 2 & 1 \\
\hline indications & Provided directions & $\begin{array}{l}\text { Generic indication/ } \\
\text { medium probability of } \\
\text { profiting }\end{array}$ & 1 & & \\
\hline & & $\begin{array}{l}\text { Specific indication/high } \\
\text { probability of profiting }\end{array}$ & 2 & & \\
\hline & & & & 7.7 & 5 \\
\hline
\end{tabular}


The HBIM models and environment discussed so far are to play a crucial role also in 'regenerative' projects. First, because the entire building sector is quickly embracing the BIM philosophy. Secondarily because regenerative designs could benefit more than other approaches from the HBIM ability to merge heterogeneous information without losing the possibility of retrieving and combining it in a creative way. In this framework, the wide access to HBIM models and to their informative background will actually embody the so-called 'digital operational archives' envisaged by the Carta del Rilievo Architettonico, where a 'rational synthesis of data' would encourage the integration of skills and 'the osmosis of disciplinary or professional knowledge'.

\section{References}

Acierno, M., Cursi, S., Simeone, D., \& Fiorani, D. (2017). Architectural heritage knowledge modelling: An ontology-based framework for conservation process. Journal of Cultural Heritage, 24, 124-133.

Addison, A. C., \& Gaiani, M. (2000). Virtualized architectural heritage: New tools and techniques. IEEE MultiMedia Journal, 7(2), 26-31.

Apollonio, F. I., Gaiani, M., \& Sun, Z. (2013). 3D modeling and data enrichment in digital reconstruction of architectural heritage. International Archives of the Photogrammetry, Remote Sensing and Spatial Information Sciences, XL-5/W2, 43-48.

Baik, A. (2017). From point cloud to Jeddah heritage BIM Nasif historical house-case study. Digital applications in archaeology and cultural heritage, 4, 1-18. https://doi.org/10.1016/j. daach.2017.02.001. Accessed 10 Sept 2020.

Bengio, Y., Courville, A., \& Vincent, P. (2013). Representation learning: A review and new perspectives. IEEE Transactions on Pattern Analysis and Machine Intelligence, 35(8), 1798-1828.

Bianchini, C. (2014). Survey, modeling, interpretation as multidisciplinary components of a knowledge system. SCIRES-IT-SCIentific RESearch and Information Technology, 4(1), 15-24.

Bianchini, C., Inglese, C., \& Ippolito, A. (2016a). Il contributo della Rappresentazione nel building information Modeling (BIM) per la gestione del costruito/the role of BIM for representation and managing of built and historic artefacts. Disegnarecon, 9, 10.1-10.9.

Bianchini, C., Inglese, C., \& Ippolito, A. (2016b). I Teatri Antichi del Mediterraneo come esperienza di rilievo integrato $\mid$ the ancient theatres of the Mediterranean as integrated survey experience. Sapienza Edizioni.

Bianchini, C., Inglese, C., Ippolito, A., Maiorino, D., \& Senatore, L. J. (2017). Building information Modeling (BIM): Great misunderstanding or potential opportunities for the design disciplines? In A. Ippolito \& M. Cigola (Eds.), Handbook of research on emerging Technologies for Digital Preservation and Information Modeling (pp. 67-90). Hershey, PA: IGI Global.

Bianchini, C., \& Nicastro, S. (2018). The definition of the Level of Reliability: a contribution to the transparency of Historical-BIM processes. Dn. Building information modeling, data \& semantics, 2, 46-59. http://www.dienne.org/. Accessed 10 Oct 2020.

Bianchini, C., \& Russo, M. (2018). Massive 3D acquisition of CH. In 3rd Digital Heritage International Congress (DigitalHERITAGE) held jointly with 2018 24th International Conference on Virtual Systems \& Multimedia (VSMM 2018) Proceeding of VSMM Congress, 26-30 October 2018. San Francisco, CA: IEEE. https://doi.org/10.1109/ DigitalHeritage.2018.8810069.

Bianchini, C., Viscogliosi, A., \& Aglietti, A. (2017). Innovative digital heuristic approaches in architectural historical research. In Proceedings of the 21st International Conference Information Visualisation (IV) 11-14 July 2017. London: IEEE. https://doi.org/10.1109/ iV.2017.47. Accessed 10 October 2020. 
Brusaporci, S., Maiezza, P., \& Tata, A. (2018). A framework for architectural heritage HBIM semantization and development. The International Archives of the Photogrammetry, Remote Sensing and Spatial Information Sciences, XLII-2, 179-184. https://doi.org/10.5194/ isprs-archives-XLII-2-179-2018.

Brusaporci, S., \& Trizio, I. (2013). La Carta di Londra e il patrimonio architettonico: riflessioni circa una possibile implementazione. SCIRES-IT SCIentific RESearch and Information Technology, 3(2), 55-68.

Carbonara G. (2009). Atlante del Restauro architettonico. Torino: UTET.

Denard, H. (2016). A new introduction to the London charter. Paradata and transparency in virtual heritage. In A. Bentkowska-Kafel \& H. Denard (Eds.), Paradata and transparency in virtual heritage (pp. 57-71). London: Routledge Taylor and Francis Group.

Docci, M., Ippolito, A., \& Bianchini, C. (2011). Contributi per una teoria del rilevamento architettonico I papers for a theory of architectural survey. Disegnare Idee Immagini, Drawings Ideas Images, 42, 34-41.

Fallavolita, F., Ballabeni, M., Foschi, R., \& Perugini, G. (2015). Semantic description of the threedimensional models of Bologna porches. SCIRES.IT SCIentific RESearch and Information Technology Ricerca Scientifica e Tecnologie dell'Informazione, 5(1), 31-40.

Grussenmeyer, P., Landes, T., Voegtle, T., Ringle, K. (2008). Comparison methods of terrestrial laser scanning, photogrammetry and tacheometry data for recording of cultural heritage buildings. The International Archives of the Photogrammetry, Remote Sensing and Spatial Information Sciences, XXXVII, B5. Beijing, 213-218.

Inzerillo, L., Lo Turco, M., Parriniello, S., Santagati, C., \& Valenti, G. M. (2016). BIM e Beni architettonici: Verso una metodologia operativa per la conoscenza e la gestione del patrimonio culturale/BIM and architectural heritage: Towards an operational methodology for the knowledge and the management of cultural heritage. Disegnarecon, 9, 16.1-16.9.

Logothetis, S., Karachaliou, E., \& Stylianidis, E. (2017). From OSS CAD to BIM for cultural heritage digital representation. The international archives of the photogrammetry, remote sensing and spatial information sciences. In $3 d$ virtual reconstruction and visualization of complex architectures (Vol. 1-3, pp. 439-445).

López, F. J., Lerones, P. M., Llamas, J., Gómez-García-Bermejo, J., \& Zalama, E. (2018). A Review of Heritage Building Information Modeling (H-BIM). Multimodal Technologies and Interaction, 2(2), 21.

Popper, K. (1963). Conjectures and refutations: The growth of scientific knowledge. London: Routledge.

Quattrini, R., Pierdicca, R., \& Morbidoni, C. (2017). Knowledge-based data enrichment for HBIM: Exploring high quality models using the semantic-web. Journal of Cultural Heritage, 28, 129-139.

Rossi, A., \& Palmieri, U. (2019). LOD per il patrimonio architettonico: la modellazione BIM per la fabbrica di Solimene. Diségno, 4, 213-224.

Open Access This chapter is licensed under the terms of the Creative Commons Attribution 4.0 International License (http://creativecommons.org/licenses/by/4.0/), which permits use, sharing, adaptation, distribution and reproduction in any medium or format, as long as you give appropriate credit to the original author(s) and the source, provide a link to the Creative Commons license and indicate if changes were made.

The images or other third party material in this chapter are included in the chapter's Creative Commons license, unless indicated otherwise in a credit line to the material. If material is not included in the chapter's Creative Commons license and your intended use is not permitted by statutory regulation or exceeds the permitted use, you will need to obtain permission directly from the copyright holder.

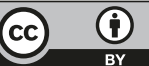

